\title{
Copper-Modified Boron-Doped Diamond (Cu/Bdd) Electrode for the Electrochemical Detection of Paclitaxel and Oxaliplatin in Aqueous Solutions
}

\author{
SORINA-CLAUDIA NEGREA ${ }^{1,2 *}$, LIDIA ANI DIACONU ${ }^{1}$, VALERIA NICORESCU ${ }^{1}$, ANAMARIA BACIU ${ }^{3}$, \\ ANIELA POP ${ }^{3}$, FLORICA MANEA ${ }^{3}$ \\ ${ }^{1}$ National Institute of Research and Development for Industrial Ecology (INCD ECOIND), 300431, Timisoara Branch, \\ Romania \\ 2"Gheorghe Asachi" Technical University of Iasi, Department of Environmental Engineering and Management, 700050, \\ Iasi, Romania \\ ${ }^{3}$ Politehnica University of Timisoara, Department of Applied Chemistry and Engineering of Inorganic Compounds and \\ Environment, Faculty of Industrial Chemistry and Environmental Engineering, 6 V.Parvan, 300223, Timisoara, Romania
}

\begin{abstract}
The aim of this study was to obtain a simple and fast modified electrode for the detection of paclitaxel (PCX) and oxaliplatin (OXA) in aqueous solution. PCX and OXA are some of the most used cytostatic drugs suitable to treat various types of cancer, e.g., ovarian, breast, lung, cervical, pancreatic, Kaposi's sarcoma. The development of an easy method for its determination is required for both the dosage in cancer therapy and due its potential presence in environment and especially, in water samples. Boron doped diamond (BDD) electrode was electrochemically modified with copper $(\mathrm{Cu})$ by chronoamperometry $(\mathrm{CA})$ operated under optimized conditions of $0.75 \mathrm{~V} / \mathrm{SCE}$ potential level for 120 minutes. Copper-modified boron-doped diamond (Cu/BDD) exhibited the electrocatalytic effect towards the paclitaxel and oxaliplatin oxidation, allowing their detection in $0.1 \mathrm{M} \mathrm{NaOH}$ supporting electrolyte. The limiting anodic current was noticed at the potential value of $+0.75 \mathrm{~V} / \mathrm{SCE}$ that increased linearly with PCX concentration, and at the potential value of $+0.6 \mathrm{~V} / \mathrm{SCE}$ for the oxaliplatin. Some mechanical aspects related to the PCX oxidation at $\mathrm{Cu} / \mathrm{BDD}$ electrode in $0.1 \mathrm{M} \mathrm{NaOH}$ supporting electrolyte were determined using cyclic voltammetry $(C V)$ recorded at various scan rates. $C V$ was based on compounds detection and achieved the sensitivity of $0.65 \mu \mathrm{A} / \mu \mathrm{M}$ for oxaliplatin and respective, $5.47 \mu \mathrm{A} / \mu \mathrm{M}$ for paclitaxel.
\end{abstract}

Keywords: copper, electrochemical detection, modified boron-doped diamond electrode paclitaxel, oxaliplatin

The urban population of the world has grown rapidly in the last decades. According to Jensen and $\mathrm{Wu}$ [1], 54\% of the world's population (approximately 3.9 billion people) lived in urban areas in 2014, this proportion is expected to increase to $66 \%$ by the year 2050 . Population growth has brought with it several environmental impacts, and the water is one of the most affected resources in terms of availability loss and quality deterioration of surface and groundwaters [2], which should affect the human life through the urban water cycle. One of the important factors of the urban cycle water is pollutant flow, which is mainly associated with anthropogenic water use [3], related to handling of different substances used in day-to-day life that has generated a wide range of conventional pollutants. Additionally, there is an important series of new contaminants that are called emerging (or micro-) pollutants [4-6], with a wide spectrum of concentrations (ranging from $\mathrm{ng} / \mathrm{L}$ to $\mathrm{mg} / \mathrm{L}$ ) [7]. Many researches have been dedicated in defining and characterizing emerging pollutants for their regulation.

The European Environmental Agency considers that EPs (refered to also as "hazardous substances and chemicals") should be closely monitored as concentrations and effects, since they are increasingly being found in water bodies across the EU (EEA, 2012) [8]. It has also been found that over the last decade many environmental researchers have reported the harmful effects of pharmaceuticals. Pharmaceutical compounds have become indispensable for our modern society. It has also been found that the presence of large amounts of pharmaceutical products are discharged continuously and directly into effluents from conventional wastewater treatment plant, into the rivers through untreated wastewaters, or incomplete removal or terrestrial run-off [9]. Among the most harmful classes of pharmaceuticals are cytostatic drugs.

*email: ecoind.tm@gmail.com, Phone: 0739537611 
These drugs were found to be among the most toxic, causing serious adverse effects on the population. Due to the significant increase in the number of cancer cases, it has been found that the presence of these cytostatic in the environment is steadily increasing [10]. Thus, it is necessary to detect and monitor of these cytostatics in water samples. The detection of emerging pollutants by electrochemical methods is useful because she presents many advantages such as versatility, energy efficiency, suitable for automation and reduced costs [11]. Electrochemical methods are considered to be very promising for the detection of cytostatics in water, and in recent years, conductive diamond electrodes for electrochemical detection has been a major focus of development studies. Several research studies have shown that the BDD electrode exhibits remarkable properties in electrochemical applications, properties such as stability and reproducibility. Also, the use of the BBB electrode led to very promising results in the electrochemical detection of pesticides [12]. It has also been found that by modifying the interface of the electrode with various materials, for example, graphene, carbon nanotubes, carbon nanotubes, the electroactive surface area and the electrocatalytic effect was larger. For exemple, a study showed improvement of the electrode surface BDD using graphene and silver as materials for to modified the surface electrode, thus BDDGRAg electrode made possible the selective detection of CR and PQ in the real surface water [13]. Sometimes, for the detection of various classes of compounds or to enhance the electroanalytical parameters it is necessary the modification of the boron-doped diamond electrode. For example, goldmodified boron-doped diamond electrode was reported for the detection of $17 \beta$-estradiol [14] and bismuth particles Nafion covered boron-doped diamond electrode for simultaneous and individual detection of paracemtaol and caffeine [15].

The aim of the present study was to develop an electrochemical method for the detection of two cytostatics, paclitaxel (PCX) and oxaliplatin (OXA) in aqueous solutions using a copper-modified boron-doped diamond (Cu/BDD) electrode envisaging monitoring their presence in the aquatic environment, including effluents discharged into the environment. The electrochemical behaviors of both cytostatics on commercial boron-doped diamond electrode showed that no electrochemical signal was found. The presence of copper on the boron-doped diamond showed the appearance of the anodic oxidation peaks for both cytostatics at different potential value.

\section{Experimental part \\ Materials and methods}

The electrochemical experiments were performed using an Autolab Pontentiostat / Galvanostat PGStat 302 (EcoChimie, The Netherlands) controlled with GPES 4.9 software and three-electrode cell consisted of saturated calomel electrode as reference (SCE), platinum electrode as counter-electrode and the copper modified/unmodified boron-doped diamond electrode modified ( $\mathrm{Cu} / \mathrm{BDD}$ and $\mathrm{BDD})$ as working electrodes.

The commercial BDD electrode produced by Windsor Scientific Ltd. (for electroanalytic use, with a boron content of about 0.1 was modified by chronoamperometry (CA) using $0.05 \mathrm{M}$ copper sulphate solution operated at various working conditions. $0.1 \mathrm{M}$ sodium hydroxide $(\mathrm{NaOH})$ supporting electrolyte was used for electrochemical detection studies. Stabilization of the electrode prior to use was made by 10 repetitive cyclic voltammograms recorded in the potential range between -1 and $+1 \mathrm{~V} / \mathrm{SCE}$. $\mathrm{NaOH}$ used was analytical-grade reagent from Merck, and oxaliplatin and paclitaxel were used as received from Sigma-Aldrich. All solutions were prepared with deionised water. Morpho-structural characteristics of the electrode surface were determined by scanning electron microscopy (SEM) using Inspect $S$ PANalytical. All measurements were carried out at room temperature without temperature control. Cyclic voltammetry and chronoamperometry were electrochemical techniques used forelectrochemical characterization and analytical applications.

\section{Results and discussions}

\section{Structural and Morphological Characterization}

The surfaces of BDD and $\mathrm{Cu} / \mathrm{BDD}$ electrodes were characterized comparatively through scanning electron microscopy (SEM) and the SEM images are presented in Figure $1 \mathrm{a}$ and $\mathrm{b}$. As it can be seen form Fig.1b, the surface of $\mathrm{BDD}$ is covered with small $\mathrm{Cu}$ particles characterized by relative good distribution.

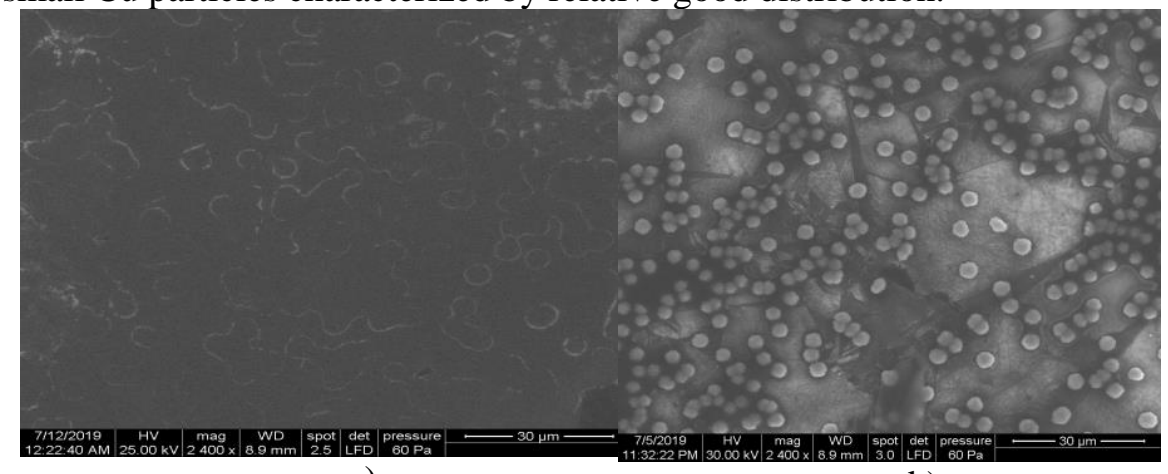

a)

b)

Fig. 1. SEM images of: BDD electrode (a) and Cu/BDD electrode (b) 
In order to develop a voltammetric and / or amperometric electrochemical method, the electrochemical behaviour of analyte on the electrode surface is required. The comparative electrochemical behaviour of each cytostatic on $\mathrm{Cu} / \mathrm{BDD}$ and BDD are shown in Figures 2 and 3. Figures $2 \mathrm{a}$ and $\mathrm{b}$ present the cyclic voltammograms recorded on the BDD in $0.1 \mathrm{M} \mathrm{NaOH}$ supporting electrolyte in the presence of $25 \mu \mathrm{M}$ oxaliplatin (Fig. 2a) and $12 \mu \mathrm{M}$ paclitaxel (Fig. 2b). A slight increase in the anode current in the potential range where oxygen discharge takes place and thus, this process covers the oxidation process of the two cytostatics, which leads to the impossibility of detection on the BDD electrode. In this context, taking into account the results reported in literature for the BDD [16-18] electrode surface modification, the copper particles $(\mathrm{Cu})$ were deposited on the surface of the BDD electrode. The electrochemical behavior of oxaliplatin and paclitaxel on the copper modified BDD electrode ( $\mathrm{Cu} / \mathrm{BDD}$ ) was also studied by cyclic voltammetry and the results obtained are shown in Figure 3a (for oxaliplatin) and Figure 3b (for paclitaxel).

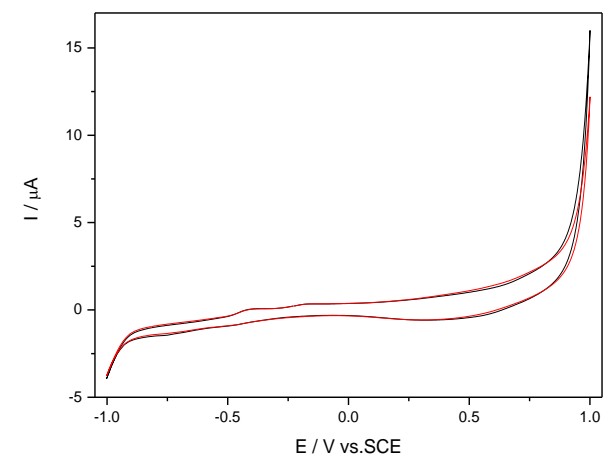

a)

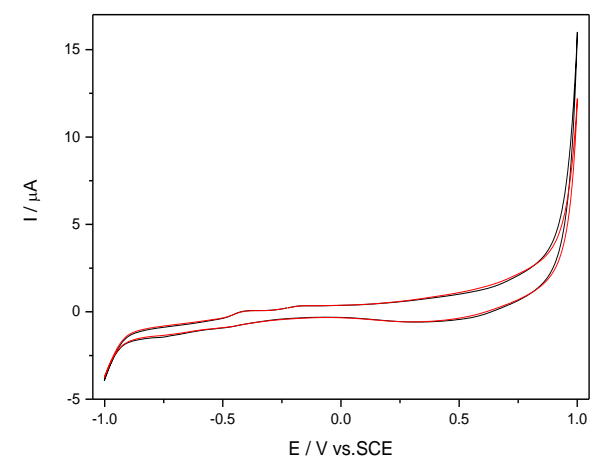

b)

Fig. 2. Cyclic voltammogram recorded at the BDD electrode in $0.1 \mathrm{M} \mathrm{NaOH}$ supporting electrolyte in the presence of: $25 \mu \mathrm{M}$ OXA (a) and $12 \mu \mathrm{M}$ PCX (b)

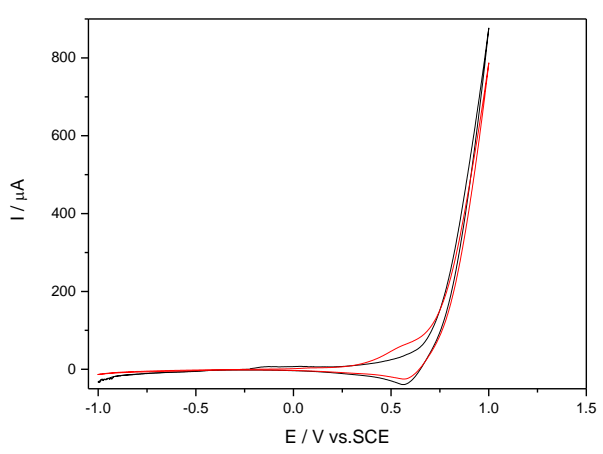

a)

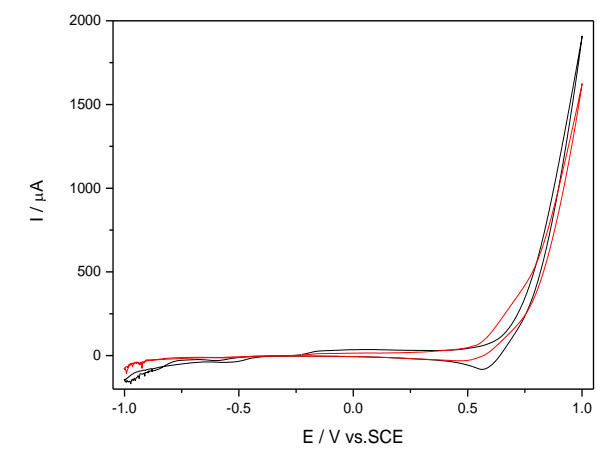

b)

Fig. 3. Cyclic voltammogram recorded at the $\mathrm{Cu} / \mathrm{BDD}$ electrode in $0.1 \mathrm{M} \mathrm{NaOH}$ supporting electrolyte in the presence of $25 \mu \mathrm{M}$ OXA (a) and $12 \mu \mathrm{M}$ PCX (b)

For both cytostatics a significant increase in anodic current was observed prior to oxygen discharge, indicating the potential of the $\mathrm{Cu} / \mathrm{BDD}$ electrode to be used to develop an electrochemical detection method. Oxaliplatin oxidation peak was observed at electrochemical potential $+0.6 \mathrm{~V} / \mathrm{SCE}$ and for paclitaxel it was observed at $+0.75 \mathrm{~V} / \mathrm{SCE}$. In order to obtain the best electroanalytic signal, it was necessary to optimize the electrodeposition conditions for the surface of the boron doped diamond electrode (BDD). In a first step, optimization of the copper electrodeposition potential (Cu) on the surface of the BDD electrode was followed by the potential variation in the range from $-0.15 \mathrm{~V}$ to $-1.2 \mathrm{~V} / \mathrm{SCE}$. The optimization of the deposition potential was achieved while maintaining the time at $60 \mathrm{~s}$ in the presence of $25 \mu \mathrm{M}$ oxaliplatin. Deposition potential of $-0.15 \mathrm{~V},-0.25 \mathrm{~V},-0.35 \mathrm{~V},-0.5 \mathrm{~V},-0.75 \mathrm{~V},-1 \mathrm{~V},-1.2 \mathrm{~V}$ were applied. The best signal was obtained for applying the electrodeposition potential of $-0.75 \mathrm{~V} / \mathrm{SCE}$ (Figure $4 \mathrm{a}$ ). The second step was to optimize the electrodeposition time of copper $(\mathrm{Cu})$ on the surface of the BDD electrode by varying the time in the range from $30 \mathrm{~s}$ to 150s. The optimization of the deposition time was achieved while maintaining the deposition potential at $-0.75 \mathrm{~V} / \mathrm{SCE}$. Deposition times of $30 \mathrm{~s}, 60 \mathrm{~s}, 90 \mathrm{~s}, 120 \mathrm{~s}, 150 \mathrm{~s}$ were applied. The best signal was obtained for applying the electrodeposition time of 120 s (Figure $4 \mathrm{~b}$ ). 


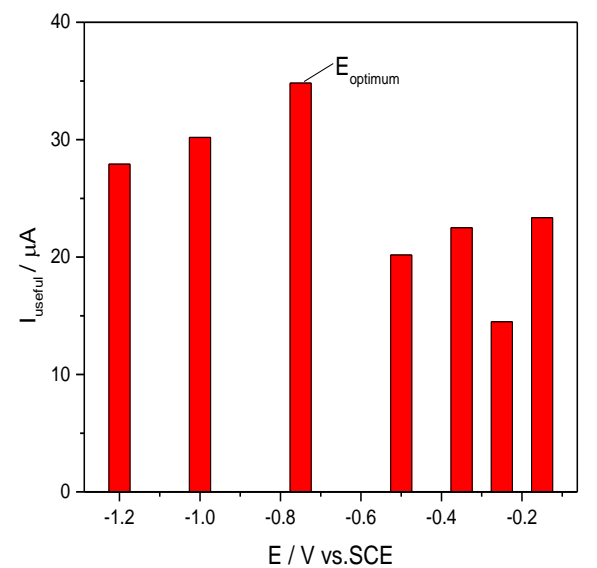

a)

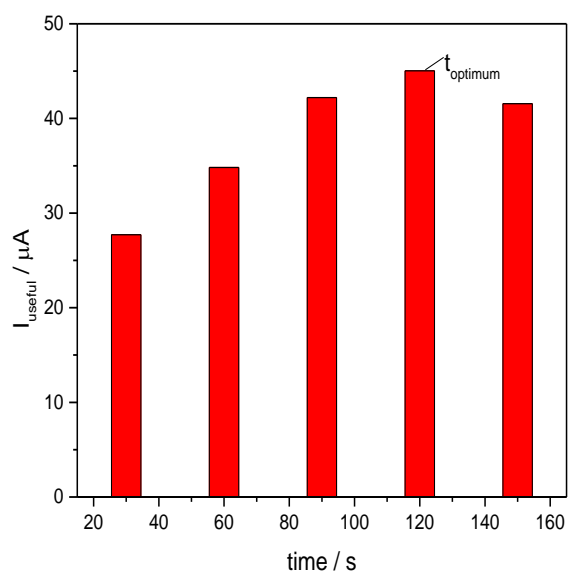

b)

Fig. 4. Useful signal for the detection of oxaliplatin function of: a)- the copper deposition potential on the BDD surface; b)- the copper deposition time on BDD surface

To elucidate aspects of the mechanism of the oxidation process underlying the development of the detection method, the influence of scan rate on the cyclic voltammograms recorded in the presence of $25 \mu \mathrm{M}$ paclitaxel compared to the absence of paclitaxel (only supporting electrolyte) was studied and the results are shown in Figures 5 and Figures 6.

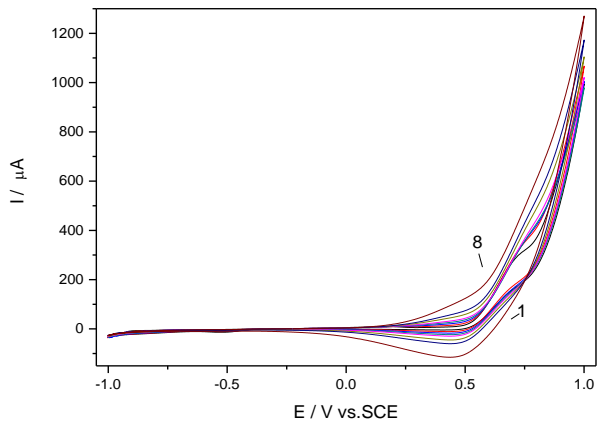

a)

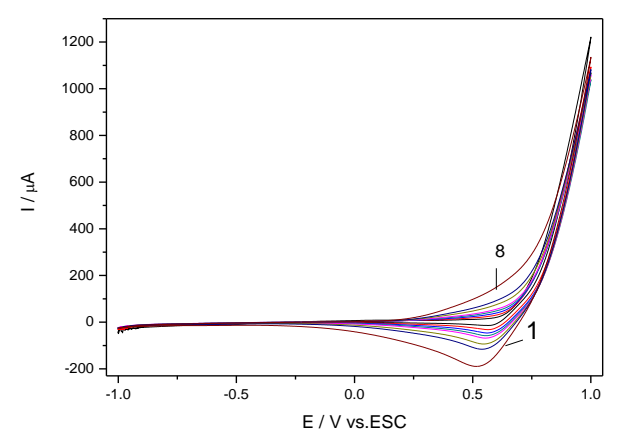

b)

Fig. 5. Cyclic voltammograms recorded at the $\mathrm{Cu} / \mathrm{BDD}$ electrode at various scan rates $0.01 ; 0.02 ; 0.03 ; 0.04 ; 0.05$; $0.075 ; 0.1 ; 0.2 \mathrm{Vs}-1$ (curves $1-8$ ) in $25 \mu \mathrm{M}$ PCX (a) and $0.1 \mathrm{M} \mathrm{NaOH}$ supporting electrolyte (b)

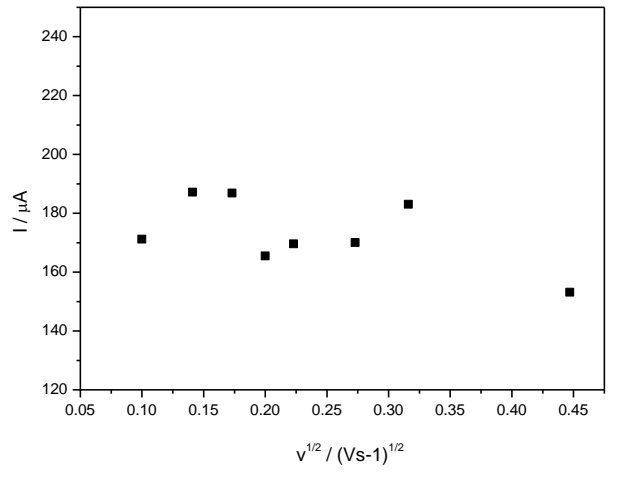

a)

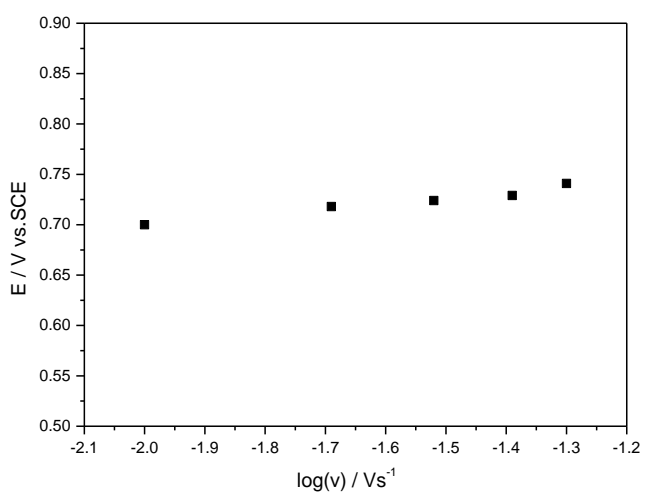

b)

Fig. 6. a) Dependence of anodic peak current vs. square root of the scan rate; b) Dependence of anodic peak potential vs. logarithm of the scan rate

The current variation with the scan rate is not linear, which shows that there is no characteristic linear diffusion of the macroelectrod, but rather a significant involvement of the electrode surface in the electrode process. An increase in the anode and cathode current within the potential range from 0 to $0.5 \mathrm{~V} / \mathrm{SCE}$ is noticed before the oxidation process of paclitaxel, which is also observed in the absence of paclitaxel (Figure 5b). This phenomenon can be associated with the oxidation/reduction process of $\mathrm{Cu} / \mathrm{Cu}^{2+}$. For the determination of OXA and PCX using $\mathrm{Cu} / \mathrm{BDD}$ electrode to develop the electroanalytical methods were applied two electrochemical techniques. Thus, $\mathrm{CV}$ at the scan rate of $0.05 \mathrm{Vs}^{-1} \mathrm{was}$ applied for OXA (Figure 7) and CV (Figure 8) and CA (Figure 9) were applied for PCX. The sensitivity of $0.65 \mu \mathrm{A} / \mu \mathrm{M}$ was achieved for OXA detection the sensitivity of $5.47 \mu \mathrm{A} / \mu \mathrm{M}$ was obtained for PCX using $\mathrm{CV}$ on $\mathrm{Cu} / \mathrm{BDDE}$ electrode. 

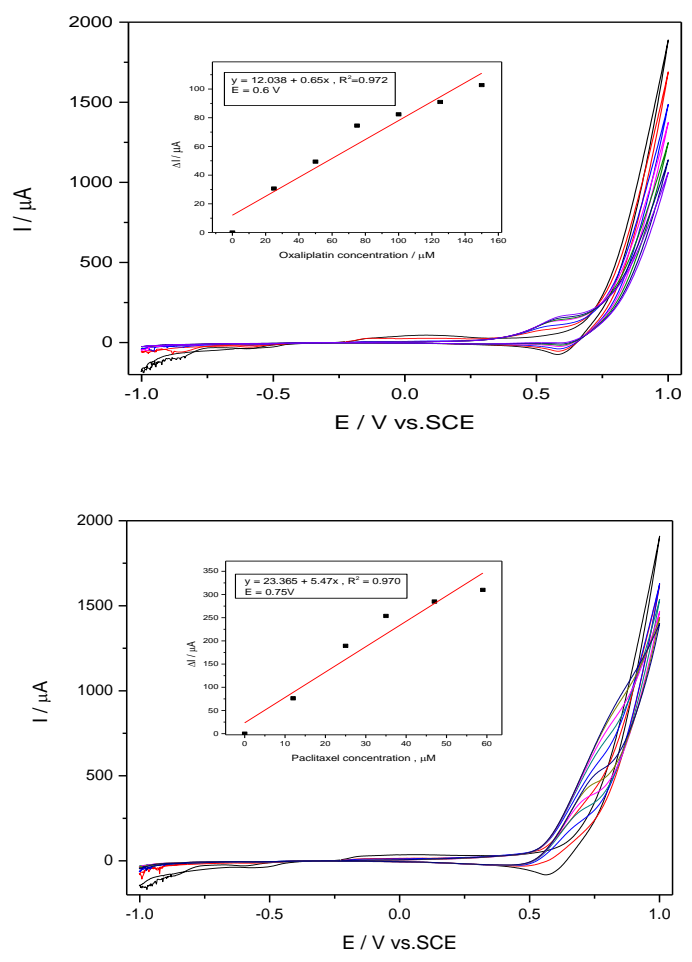

Fig.7.Cyclic voltammograms recorded at the $\mathrm{Cu} / \mathrm{BDD}$ electrode in $0.1 \mathrm{M} \mathrm{NaOH}$ supporting electrolyte and in the presence of various OXP concentrations:25-150 $\mu \mathrm{M}$ OXP. Inset: Calibration plots of the currents versus OXP concentrations at potential value of $+0.6 \mathrm{~V} / \mathrm{SCE}$
Fig. 8. Cyclic voltammograms recorded at the $\mathrm{Cu} / \mathrm{BDD}$ electrode in $0.1 \mathrm{M} \mathrm{NaOH}$ supporting electrolyte and in the presence of various PCX concentrations: $12-70 B \mu \mathrm{M}$ PCX. Inset:

Calibration plots of the currents versus PCX concentrations at potential value of $+0.75 \mathrm{~V} / \mathrm{SCE}$

Considering that $\mathrm{CA}$ is regarded to be the most useful technique for electroanalysis applications because it is the easiest to operate and automated and quite for in-field detection applications, this technique was tested for PCX detection taking into account the best CV based detection results above-presented. For electroanalysis applications, chronoamperometry can be applied in stirring solutions using the standard method of continuous addition of the target analyte or its successive addition. Since chronoamperometry involves recording the current at certain detection potential values, the selection of the detection potential considered the cyclic voltammogram results. Based on the cyclic voltammogram shape, the selected detection potential was $0.8 \mathrm{~V} / \mathrm{SCE}$. A linear dependence of the current with PCX concentration was noticed and the calibration curve is presented in the inset of Figure 9.

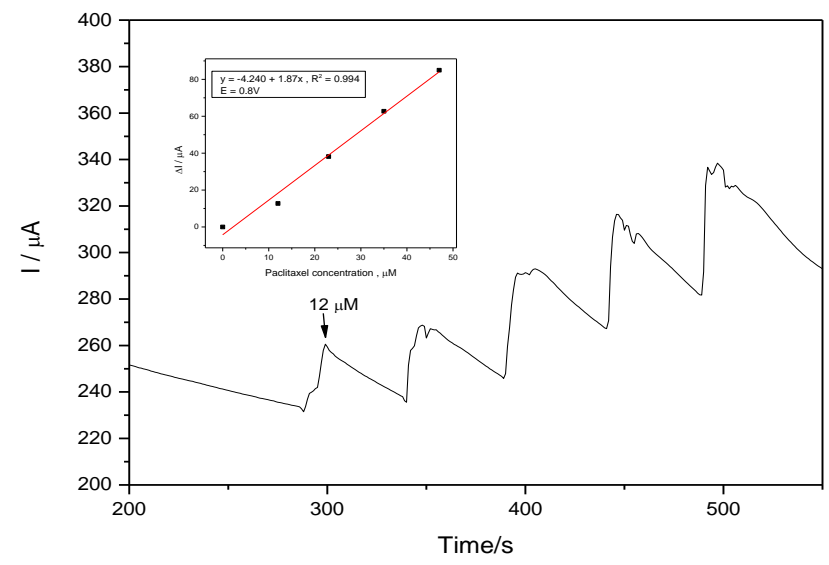

Fig. 9. Chronoamperogram (CA) recorded at the $\mathrm{Cu} / \mathrm{BDD}$ electrode in $0.1 \mathrm{M} \mathrm{NaOH}$ supporting electrolyte in a stirred solution by the continuous addition method in the presence of various PCX concentrations: $12-59 \mu \mathrm{M}$ PCX. Inset: Calibratio plots of the currents versus PCX concentrations a potential values of $+0.8 \mathrm{~V}$

The comparative results of the electroanalytical parameters obtained for $\mathrm{Cu} / \mathrm{BDD}$ electrode in the detection of paclitaxel and oxaliplatin are gathered in Table 1.

Table 1

ELECTROANALYTICAL PARAMETERS FOR OXA AND PCX DETECTION ON THE CU / BDD ELECTRODE

\begin{tabular}{|c|l|l|l|l|l|l|l|}
\hline Cytostatic & Technique & $\begin{array}{l}\text { Conditions, } \\
\text { E/V vs. SCE }\end{array}$ & $\begin{array}{l}\text { Sensitivity } \\
\left(\mu \mathrm{A}^{*} \mu \mathrm{M}^{-1}\right.\end{array}$ & $\begin{array}{l}\text { Correlation } \\
\text { Coefficient }(\mathrm{R}\end{array}$ & $\begin{array}{l}\text { LOD } \\
(\mu \mathrm{M})\end{array}$ & $\begin{array}{l}\mathrm{LOQ}^{\mathrm{b}} \\
(\mu \mathrm{M})\end{array}$ & $\begin{array}{l}\mathrm{RSD}^{\mathrm{c}} \\
(\%)\end{array}$ \\
\hline Oxaliolatin & $\mathrm{CV}$ & 0.6 & 0.65 & 0.972 & 2.07 & 6.89 & 0.65 \\
\hline \multirow{2}{*}{ Paclitaxel } & $\mathrm{CV}$ & 0.75 & 5.47 & 0.970 & 0.05 & 0.164 & 0.2 \\
\cline { 2 - 8 } & $\mathrm{CA}$ & 0.8 & 1.87 & 0.994 & 1.60 & 5.34 & 0.4 \\
\hline
\end{tabular}

${ }^{a}$ The limit of detection; ${ }^{b}$ The limit of quantitation; ${ }^{c}$ relative standard deviation.

It can be noticed that better sensitivity was achieved for PCX at the potential value of $+0.75 \mathrm{~V} / \mathrm{SCE}$ in comparison with OXA at the potential value of $+0.6 \mathrm{~V} / \mathrm{SCE}$ using $\mathrm{CV}$ on $\mathrm{Cu} / \mathrm{BDDE}$ electrode. The sensitivity reached using $\mathrm{CA}$ was 
lower in comparison with CV results $(1.87 \mathrm{~V} / \mathrm{SCE}$ vs $5.47 \mu \mathrm{A} / \mu \mathrm{M})$, which confirm the possible surface phenomena involving within overall anodic oxidation process responsible for the PCX detection signal.

In this study it was found that the use of $\mathrm{Cu} / \mathrm{BDD}$ modified electrode for the detection of the two cytostatics allowed a better detection limit to be obtained in comparison with other detection limits found in the literature using the BDD electrode [19].

\section{Conclusions}

Based on this study, it can be concluded that the surface of the BDD electrode can be modified with copper particles by the electrodeposition process using the chronoamperometry technique. The optimal electrodeposition parameters on the BDD surface determined on the basis of the useful electrodetection signal of oxaliplatin were found to be the electrodeposition potential of $-0.75 \mathrm{~V} / \mathrm{SCE}$ and the electrodeposition time of $120 \mathrm{~s}$. The electrochemical behaviors of oxalipatin and paclitaxel on the BDD electrode surface showed that the un-modified BDD electrode was not able to detect the two cytostatics. The surface phenomenon involving -overall oxidation process of paclitaxel was noticed based on the scan rate influence on the cyclic voltammograms recorded on the $\mathrm{Cu} / \mathrm{BDD}$ electrode. Better sensitivity was achieved for PCX $(5.47 \mu \mathrm{A} / \mu \mathrm{M})$ at the potential value of $+0.75 \mathrm{~V} / \mathrm{SCE}$ in comparison with OXA $(0.65 \mu \mathrm{A} / \mu \mathrm{M})$ using CV on $\mathrm{Cu} / \mathrm{BDDE}$ electrode. The sensitivity reached using CA was lower in comparison with CV results (1.87 V/SCE vs 5.47 $\mu \mathrm{A} / \mu \mathrm{M})$, which proved a possible fouling electrode due to the surface phenomena involving within overall anodic oxidation process responsible for the detection signal. It can be concluded that the modified $\mathrm{Cu} / \mathrm{BDD}$ electrode exhibited a good potential for the development of electrochemical methods for detection of paclitaxel and oxaliplatin in water.

Acknowledgements: The present research was partially financed by the Romanian National "Nucleu" Program, contract no. 20 N/2019 (Project code PN 19040102 ) and partially by a grant of the Romanian Ministery of Research and Innovation, project number PN-III-P1-1.2-PCCDI-20170245/26 PCCDI/2018 (SUSTENVPRO), within PNCDI III.

\section{References}

1. JENSEN, O., WU, H., Sciences Policy, 83, 2018, p. 33.

2. GUZMAN, C.P., SANCHEZ, S.U., MORA, K., BUSTOS, R. H., BARRERA, E.L., ALVAREZ, J., PINZON, M.R., J. Environ. Manage., 237, 2019, p. 408.

3. FLETCHER, T.D., SHUSTER, W., HUNT, W.F., ASHLEY, R., BUTLER, D., ARTHUR, S., TROWSDALE, S., BARRAUD, S., SEMADENIDAVIES, A., BERTRAND-KRAJEWSKI, J.-L., MIKKELSEN, P.S., RIVARD, G., UHL, M., DAGENAIS, D., VIKLANDER, M., Urban Water J., 12, 2015, p. 525.

4. PAL, A., HE, Y., JEKEL, M., REINHARD, M., GIN, K.Y.-H., Env. Int., 71, 2014, p. 46.

5. PETRE, J., GALAON, T., IANCU, V.I., NICULESCU, M., $20^{\text {th }}$ International Symposium on The Environment and the Industry, 2017, p. 237.

6. GALAON, T., PETRE, J., IANCU, V. I., CRUCERU, L., VASILE G.G., PASCU, L. F., LEHR, C.B., Rev. Chim. (Bucharest), 67, no. 8, 2016, p. 1474.

7. FARRE, M., PEREZ, S., KANTIANI, L., BARCELO, D., Trends Anal. Chem., 27, 2008, p. 991.

8. TEODOSIU C., A. F. GILCA A. F., BARJOVEANU G., FIORE S., J. Clean. Prod., 197, 2018, p. 1210.

9. PETRE, J., GALON, T., IANCU, V.I., VASILE, G., STANESCU, E., PASCU, L., F., SIMION, M., CRUCERU, L., Rev. Chim. (Bucharest), 67, no. 8, 2016, p. 1436.

10. GALAON, T., IANCU, V., PETRE, J., CRUCERU, L., NICULESCU, M., CHIRIAC, F. L., PUIU, D. M., MIHALACHE, M., $20^{\text {th }}$ International Symposium on The Environment and the Industry, 2017, p. 229.

11. IHOS, M., DRAGALINA, M., IORDACHE, I., NEIDONI, D., Rev. Chim. (Bucharest), 70, no.1, 2016, p. 304

12. POP, A., MANEA, F., FLUERAS, A., SCHOONMAN, J., Sensors, 17, p. 2033.

13. POP, A., LUNG, S., ORHA, C., MANEA, F., Int. J. Electrochem. Sci., 13, 2018, p. 2651.

14. KE, H., LIU, M., ZHUANG, L., LI, Z., FAN, L., ZHAO, G., Electrochim. Acta, 137, 2014, p. 146.

15. SADOK, I., TYSZCZUK-ROTKO, K., NOSAL-WIERCINSKA, A., Sensors Actuat. B -Chem., 235, 2016, p. 263.

16. COETSIER, C.M., SPINELLI, S., LIN, L., ROIG, B., TOURAUD, E., Env. Int., 35, 2009, p.787.

17.TOGHILL, K. E., WILDGOOSE, G. G., MOSHAR, A., MULCAHY, C., AND COMPTON, R. G., Electroanalysis, 20, 2008, p. 1731.

18. DUMiTRU, R., MANEA, F., LUPA, L., PACURARIU, C., IANCUlESCU, A., BACIU, A. M., NEGREA, S. C., J. Therm. Anal. Calorim., 128, 2017, p. 1305.

19. SVORC, L., Borovska, K., CINKOVA, K., STANKOVIC, D., M., PLANKOVA, A., Electrochim. Acta, 251, 2017 , p. 621.

Manuscript received: 31.07 .2019 